\title{
Circulating 5-Hydroxytryptamine Concentrations in Preterm Newborns
}

\begin{abstract}
R.E. Schumacher, MD, P.M. Farrell, MD, PhD, and E.B. Olson, Jr., Pho
Summary. Alterations in circulating 5-hydroxytryptamine (5-HT) concentrations play a role in the pathophysiology of respiratory failure in adults. We undertook a study to develop a micromethod and measure circulating free 5-HT concentrations in preterm newborns with and without respiratory distress. Forty-six samples of platelet-poor plasma were obtained from 29 preterm newborns with varying degrees of respiratory distress. Samples were taken on days 2-3 and 6-7 of life. For measuring 5-HT concentrations we used a precolumn sample enhancement technique followed by ion exchange HPLC with electrochemical detection. The assay allowed detection of extremely small $(50 \mathrm{pg})$ amounts of $5-\mathrm{HT}$ from small $(0.2 \mathrm{mi})$ amounts of blood. The mean 5-HT concentration on days $2-3$ was $1.77 \pm 0.74 \mathrm{ng} / \mathrm{ml}$ (mean $\pm 95 \%$ confidence fimits) and on days $6-7$ was $0.69 \pm 0.23 \mathrm{ng} / \mathrm{ml}$. This represented a significant fall in $5-\mathrm{HT}$ concentrations $(P=0.01)$. All of 16 paired serial samples fell with time $(P=0.006)$. We conclude that platelet-poor plasma 5-HT concentrations in premature newborns are low, that there is a significant decline in these values over the first week of life, and that, in contrast with adults, the presence of respiratory failure is not associated with increased free 5-HT concentrations. The low 5-HT concentrations seen in newborns may reflect the ability to increase pulmonary uptake. Pediatr Pulmonol 1987; 3:117-122.
\end{abstract}

Key words: Serotonin concentration, circulation; premature infants, low 5-HT; respiratory distress, not elevated 5-HT; micromethod; precolumn sample enhancement; electrochemical detection.

\section{INTRODUCTION}

Serotonin or 5-hydroxytryptamine $(5-\mathrm{HT})$ is a neurotransmitter and a biogenic amine with multiple vasoactive properties. It is recognized as both a vasoconstrictor and a vasodilator. Animal studies of endotoxic and hemorrhagic shock suggest an important role for $5-\mathrm{HT}$ in the pathophysiology of these disease states, with elevated pulmonary artery pressure attributed in part to elevated blood 5-HT concentration. ${ }^{1.2}$ Pretreatment with 5-HT antagonists attenuates many of the cardiovascular changes seen. ${ }^{3}$ In adult humans suffering from respiratory failure. elevated concentrations of free 5-HT (measured in platelet-poor plasma) have been observed. ${ }^{4.5}$ Moreover, in one such study, the presence of pulmonary hypertension appeared to be directly related to 5-HT concentrations measured in platelet-poor plasma.

The pulmonary vascular endothelium actively takes up and metabolizes 5-HT. Alterations in pulmonary uptake ability are seen with damaged endothelium such as in shock or prolonged hyperoxic states. ${ }^{6} 8$ A recent study using isolated perfused lungs suggests that the lung's 5HT uptake ability changes with age and that peak pulmonary uptake ability occurs at or near the time of birth. ${ }^{9}$

Given the above information, we hypothesized that premature newborns with varying degrees of extrapul- monary shunting and respiratory distress would exhibit marked alterations in circulating 5 -HT concentrations. If present, such alterations may play a role in some of the hemodynamic changes seen in the newborn respiratory distress syndrome. Given that data regarding free $5-\mathrm{HT}$ concentrations in healthy preterm newborns are lacking. and given that current electrochemical detection methods lack the necessary sensitivity, ${ }^{10}$ we undertook this study to develop a micromethod and survey circulating 5-HT concentrations in preterm newborns with and without respiratory distress.

Departments of Pediatrics and Preventative Medicine, University of Michigan Medical center. Ann Arbor. Michigan: University of Wis consin and Madison General Hospital. Madison. Wisconsin.

Received April 3. 1986: (revision) atcepted for publication October 14. 1986.

This study was supported in par by grants from the Madison (ieneral Hospital Medical-Surgical Research Foundation and U.S. Public Health Service grant HI.314.30. Dr. Schumacher conducted this study as a fellow of the American Lung Associaton.

Address correspondence and reprint requests to Dr. R.E. Schumacher. Department of Pediatrics, Section of Newhorn Services. University of Michigan Medical Center, Box 0254. L.3023 Women', Hospital, Ann Arbor. MI 48109-0254. 


\section{MATERIALS AND METHODS}

This study was approved by the Human Subjects Committee of the University of Wisconsin and the Institutional Review Board of Madison General Hospital. Fortysix samples of platelet-poor plasma were obtained from 29 preterm newborns. Gestational ages ranged from 25 to 36 weeks (mean 28.5 weeks). Samples were taken on day 2 or 3 of life $(>24,<72 \mathrm{hr})$ and/or on day 6 or 7 $(>120,<168 \mathrm{hr})$ of life. Sixteen of these represented paired serial samples. On days $2-3,17$ of 27 patients were receiving supplemental oxygen (either by hood or with positive pressure ventilation). On days 6-7, 10 of 20 were still receiving supplemental oxygen; however, no infant required any increase in the level of respiratory support. Of the 29 newborns studied, 17 had clinical and/ or radiographic findings compatible with respiratory distress syndrome, one had an isolated patent ductus arteriosus, three were ventilated for apnea, and two carried the clinical diagnosis of chronic pulmonary insufficiency of prematurity. Seven of the infants were receiving enteral nutrition, but none of them had been fed within $2 \mathrm{hr}$ of the time of blood sampling. In 37 cases, blood was taken from an umbilical artery catheter: nine samples were taken from a peripheral vein. Although varying degrees of alveolar hypoxia were present, as measured by indwelling arterial saturation catheters, transcutaneous oxygen monitors, or simultaneously drawn blood gases, no infant had $\mathrm{O}_{2}$ saturation $<85 \%$ or $\mathrm{P}_{\mathrm{O}_{2}}<50$ torr during blood sampling.

Blood $(0.5 \mathrm{ml})$ was drawn into a heparinized tube and carried on ice to a cold $\left(4^{\circ} \mathrm{C}\right)$ centrifuge. Each sample was centrifuged for $10 \mathrm{~min}$ at $2,000 \times$ gravity, and a resulting sample of $0.2 \mathrm{ml}$ platelet-poor plasma was transferred to a vial containing $2 / \mu \mathrm{g}$ of ascorbate solution $(1.2 \mathrm{~g}$ ascorbate $/ 100 \mathrm{ml})$, which served as an antioxidant. The sample was either frozen immediately in liquid nitrogen or stored at $-40^{\circ} \mathrm{C}$ for several days and subsequently transferred to liquid nitrogen.

Concentrations of 5-HT were measured using a precolumn sample enhancement technique followed by ion exchange HPLC with electrochemical detection. To precipitate protein, $5 \mu \mathrm{l}$ of $83 \%$ trichloracetic acid was added to each of the thawed samples; the denatured samples were spun at $3,000 \times$ gravity for $5 \mathrm{~min}$ and the resulting supernatant was used in $50 \mu \mathrm{l}$ aliquots for injection onto the columns (using a Rheodyne 7125 HPLC injection valve). A $2 \mathrm{~cm}$ enhancement column packed with 25-40 $\mu \mathrm{m}$ diameter strong cation exchange resin was used in the injection loop. Following injection of the sample. and with the injection valve still in the load position, the enhancement column was rinsed with 1.7 $\mathrm{ml}$ wash buffer. The injection valve was then moved to the inject position allowing the eluting buffer to carry the remaining sample from the enhancement column onto the $10 \mathrm{~cm}$ separation column packed with the same resin as in the enhancement column. The 5-HT was detected by a model LC4A ampometric detector (BAS Systems, Lafayette, IN) using a glassy carbon electrode. The potential across the electrode was set at $0.65 \mathrm{mV}$. The buffers used as the mobile phase in liquid chromotography were prepared by adding $10.5 \mathrm{~g}$ citric acid, $8.2 \mathrm{~g}$ sodium acetate. $4.8 \mathrm{~g}$ sodium hydroxide, and $2.1 \mathrm{ml}$ glacial acetic acid to I liter of water, which was degassed and filtered through a $0.45 \mu \mathrm{m}$ vacuum filter. This solution was used to prepare two buffers. The wash buffer used to rinse the enhancement column was prepared with one part of this solution and three parts water. The column elution buffer was prepared by adding $60 \mathrm{ml}$ of methanol to 1 liter of the filtered solution (final $\mathrm{pH}$ 5.1). Column flow was $0.75 \mathrm{mi} / \mathrm{min}$.

Verification of the identity of the 5-HT peak was obtained by inclusion of an internal 5-HT spike to selected newborn plasma samples. In addition, the specificity of the method was further contirmed by demonstrating that other idoleamines, catecholamines, and their principle metabolites fail to coelute with 5-HT. When known amounts of 5-HT were added to patients' plasma, no quenching phenomenon or interference could be demonstrated. Recovery rate of 5-HT was essentially $100 \%$. Final 5-HT concentrations were determined by comparing resultant peak heights with a standard curve developed by extracting and analyzing mock plasma samples ( $6 \%$ bovine albumin solution) prepared with known 5HT concentrations ranging from 0 to $100 \mathrm{ng} 5-\mathrm{HT} / \mathrm{ml}$. Prior to and after each series of analyses, multiple injections of a working standard solution of known 5-HT concentration were analyzed to correct for any variations in detector sensitivity. In addition, mock plasma samples (6\% bovine albumin solution containing a known 5-HT concentration of approximately $1,2,5,10,30$, or 100 $\mathrm{ng} / \mathrm{ml}$ ) were prepared in $2.0 \mathrm{ml}$ aliquots and stored in liquid nitrogen. To monitor independently the 5-HT assay, selected samples of these mock plasmas were extracted and analyzed in parallel with the analyses of unknown serum samples. All specimens were analyzed in duplicate. On occasions when the measured 5-HT concentration differed by more than $10 \%$ from the expected value, the mock serum extractions were repeated using 5-HT concentrations bracketing the estimated 5HT concentration of the unknown plasmas. If necessary, appropriate correction factors were applied to the unknowns. In this assay, with a pump flow of $0.75 \mathrm{ml} / \mathrm{min}$, 5-HT elution volume was $4.78 \mathrm{ml}$, and the void volume was $0.86 \mathrm{ml}$.

5-HT concentrations for different patient populations were compared using a one-way analysis of variance with posthoc analysis according to the method of Scheffe. "5- 
HT concentrations on different days were compared using an unpaired $t$ test. Serial sample concentrations were analyzed using a paired $t$ test. Population data are routinely expressed by the mean $\pm 95 \%$ confidence limits.

\section{RESULTS}

\section{Micromethod}

Our assay, allowed us to measure extremely small amounts $(<50 \mathrm{pg}$ injected) of 5-HT from small $(0.2 \mathrm{ml}$ plasma) amounts of blood (Fig. 1). We found that by using the enhancement column in the injection loop we could dramatically reduce the size of the solvent front or void volume peak commonly seen with plasma preparations such as ours. This technique, coupled with the selectivity of electrochemical detection, allowed for minimal sample handling and better resolution of the 5-HT peak without affecting 5-HT peak height.

Standard curves, constructed using mock plasma samples with known 5-HT concentrations $(0-100 \mathrm{ng} / \mathrm{ml})$, demonstrated a linear relationship between peak height (pk hgt) and 5-HT concentration ([5-HT]). The linear regression equation for a $50 \mu \mathrm{l}$ injection volume was pk hgt $(\mathrm{mm})=9.9516 \times[5-\mathrm{HT}](\mathrm{ng} / \mathrm{ml})+0.6929$ with a correlation coefficient of 0.991 . Overall day-to-day variability of the 5-HT assay estimated by the difference between the calculated and the actual concentration of 5$\mathrm{HT}$ in mock plasma (5-HT concentrations ranging from 1 to $30 \mathrm{ng} / \mathrm{ml}$ ) was $-0.59 \pm 0.71 \mathrm{ng} / \mathrm{ml}$. When this difference was expressed as a fraction of the expected 5HT concentrations, the overall variability was $0.054 \pm$ 0.061 . We also demonstrated that storing samples at $-40^{\circ} \mathrm{C}$ for 14 days did not appreciably alter sample 5HT concentrations.

\section{5-HT Concentrations in Patients}

The mean platelet-poor plasma 5-HT concentration on days $2-3$ was $1.77 \pm 0.74 \mathrm{ng} / \mathrm{ml}$ (mean $\pm 95 \%$ confidence limit), range $0.20-8.60 \mathrm{ng} / \mathrm{ml}$. On days $6-7$ the mean concentration was $0.69 \pm 0.23 \mathrm{ng} / \mathrm{ml}$, range 0.10 -

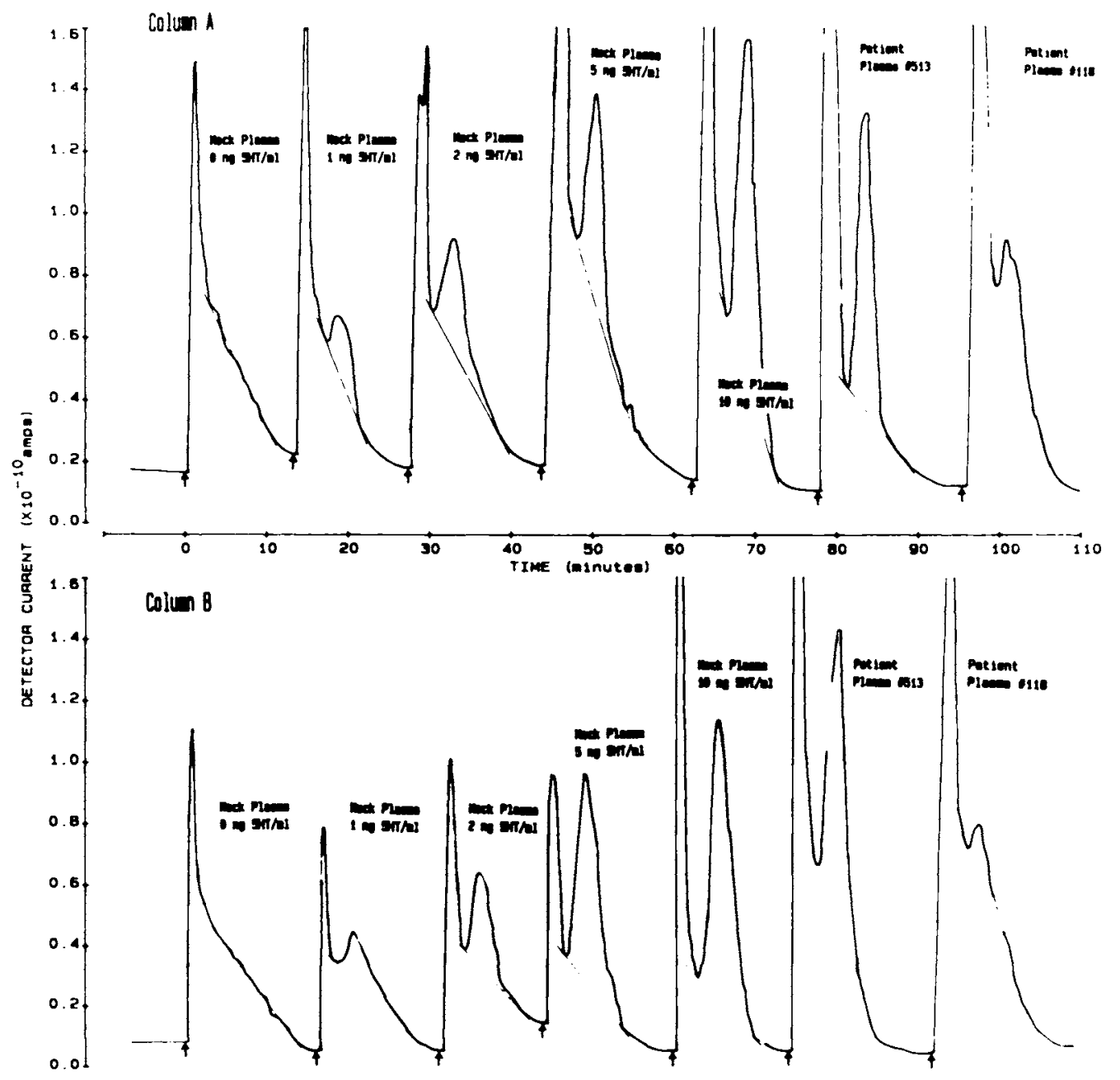

Fig. 1. Samples of mock and patient plasma containing var- sample on HPLC column A, one on column B). The initial peak ious amounts of 5-HT. Each specimen was run in duplicate (one represents a void volume. 
$2.75 \mathrm{ng} / \mathrm{ml}$. There was a statistically significant fall in concentration from days 2-3 to 6-7 $(\mathrm{P}=0.01)$. Moreover, in all 16 paired serial samples, the 5-HT concentration fell with time ( $P=0.006$; Fig. 2$)$.

We attempted to correlate 5-HT concentrations with the degree of respiratory insufficiency present (Table 1). Although on days 2-3 there was a trend towards higher 5-HT concentrations with higher inspired oxygen concentrations, using one-way analysis of variance with posthoc analysis according to the method of Schaffe, ${ }^{10}$ we were unable to demonstrate any significant difference between the groups. Of note is that the infant with the highest 5 -HT concentration $(8.6 \mathrm{ng} / \mathrm{ml})$ was receiving $100 \%$ oxygen for support.

We were unable to demonstrate a difference in 5-HT concentrations with respect to gestational age, sex, site of sampling, or platelet count. However, in that our sample size was small, our ability to detect small differences was limited.

\section{DISCUSSION}

Recently published articles have demonstrated alterations in circulating levels of various vasoactive substances such as vasoactive intestinal peptide, angiotensin II, and various prostaglandins in the neonatal respiratory distress syndrome. ${ }^{12-14}$ Our assay allowed us to measure extremely small and previously unreported free 5-HT concentrations from minimal amounts of blood. We have demonstrated that platelet-poor plasma concentrations of the vasoactive amine 5-HT are exceedingly low in the preterm neonate and that there appears to be a small but significant fall in this concentration during the first week of life. In adults, plasma 5-HT concentrations have been reported to be significantly elevated in patients with respiratory failure. ${ }^{4}$ In our laboratory, the normal adult control value for platelet-free plasma 5-HT concentration is $8.9 \pm 3.8 \mathrm{ng} / \mathrm{ml}$ (mean $\pm 95 \%$ confidence limit), range $3.6-16.0 \mathrm{ng} / \mathrm{ml}$, which compares favorably with adult norms generated by similar detection methods. ${ }^{15}$ Preterm infants with respiratory distress have free 5-HT concentrations five to ten times lower than the values we find in normal adults.

Previous attempts to measure blood (platelet-bound and -free) 5-HT concentrations in newborns met with

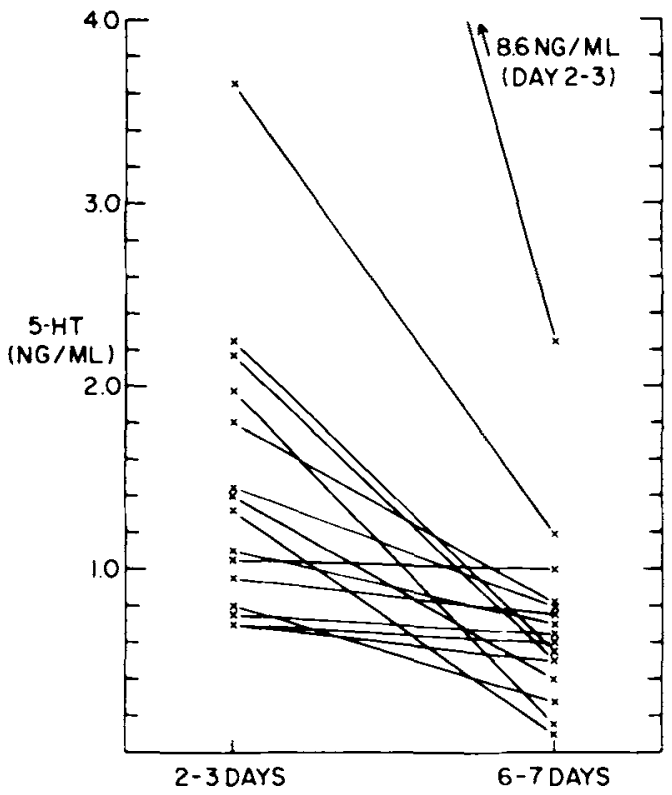

Fig. 2. Platelet-poor plasma 5-HT concentrations in 16 premature infants on days 2-3 and 6-7. All 16 infants show a fall in 5-HT concentration over time $(P=0.006)$. The infant with the highest value $(8.6 \mathrm{ng} / \mathrm{ml})$ was receiving $100 \% \mathrm{O}_{2}$ for respiratory support.

varying amounts of success. A study measuring whole blood 5-HT taken from umbilical blood vessels at delivery suggested that the fetus is capable of producing 5-HT and that fetal blood concentrations were equal to or greater than maternal levels. ${ }^{16}$ This was in contrast to other studies that found very low whole-blood 5-HT concentrations during the first few weeks of life. ${ }^{17-19}$ Explanations for these low blood 5-HT concentrations in the newborn centered around immaturity of enzyme systems involved in 5-HT synthesis, pyridoxine deficiency (a necessary cofactor for 5-HT synthesis), decreased capacity for 5-HT uptake by neonatal platelets, or perhaps delayed release reaction of 5-HT from platelets of newborns. The fact that cord-blood 5-HT concentrations can be high and that 5-HT-containing cells have been demonstrated in lung and gut from very early in gestation conflicts with the hypothesis of general enzyme immaturity as a cause for low blood 5-HT concentration. Pyridoxine deficiency may contribute to low 5-HT

TABLE 1-Relationship Between 5-HT Concentrations and Respiratory Insufficiency (Required $\mathrm{Fi}_{\mathrm{O}_{2}}$ )

\begin{tabular}{|c|c|c|c|c|c|}
\hline $\mathrm{Fi}_{\mathrm{O}_{2}}$ & $\begin{array}{c}\text { Gestational } \\
\text { age } \\
\text { (average, weeks) }\end{array}$ & $\begin{array}{c}\text { Average } \mathrm{Fi}_{\mathrm{O}_{2}} \\
\text { days 2-3 }\end{array}$ & $\begin{array}{c}{[5-\mathrm{HT}]} \\
\text { days } 2-3 \\
(\mathrm{ng} / \mathrm{ml})^{\mathrm{h}}\end{array}$ & $\begin{array}{l}\text { Average } \mathrm{Fi}_{\mathrm{O}_{2}} \\
\text { days } 5-6\end{array}$ & $\begin{array}{c}{[5-\mathrm{HT} \mid} \\
\text { days } 5-6 \\
(\mathrm{ng} / \mathrm{ml})^{\mathrm{h}}\end{array}$ \\
\hline$>0.30$ & 28.9 & $\begin{array}{c}0.56 \\
(0.35-1.0)^{a}\end{array}$ & $1.97 \pm 1.63$ & 0.50 & $0.10(n=1)$ \\
\hline $0.25 \leqslant 0.30$ & 28.5 & 0.28 & $1.73 \pm 0.42$ & 0.28 & $0.98 \pm 1.38$ \\
\hline$\leqslant 0.25$ & 30.0 & 0.23 & $1.56 \pm 1.02$ & 0.22 & $0.65 \pm 0.19$ \\
\hline
\end{tabular}

${ }^{\text {aRange. }}$

bean $\pm 95 \%$ confidence limit. 
concentrations, yet, to achieve such concentrations in virtually all newborns tested, one must hypothesize that all newborns are pyridoxine-deficient; this does not fit with the data available on pyridoxine in the newborn. ${ }^{20}$ A decreased capacity for platelet uptake of 5-HT could lead to low whole-blood 5-HT levels but would likely lead to elevated platelet-poor 5-HT levels rather than the low 5-HT concentrations found in the present study. Moreover, platelet uptake of 5-HT is reported as normal in newborn. ${ }^{21}$ A delayed release reaction of 5-HT from neonatal platelets has been demonstrated ${ }^{20}$ and could lower platelet-free plasma concentrations but not the whole blood levels noted by others. In contrast, Suarez et $\mathrm{al}^{22}$ have found elevated products of platelet degranulation in plasma of neonates. Platelet degranulation would be expected to increase the amount of 5-HT present in plasma.

Pulmonary endothelial cells compete with platelets for uptake of free 5-HT. A recent study showing that the 5HT uptake ability of the pulmonary endothelium seems to peak at or near the time of birth offers an additional explanation for low 5-HT concentrations, that of increased competition with platelets for 5-HT uptake. ${ }^{10}$ This same observation of increased uptake ability, coupled with recent observations on the role of 5-HT in the newborn's pulmonary vascular response, ${ }^{23}$ led us to speculate on the vulnerability of newborns with respiratory distress to large fluctuations in circulatory 5-HT concentrations.

In clinical studies with adults, the role of 5-HT as a vasoconstrictor appears to be important. In one clinical trial of a specific 5-HT blocker, ketanserin, the drug was administered to patients with respiratory failure with resultant reductions in systemic and pulmonary artery pressure. ${ }^{24}$ Excessive 5-HT concentrations in blond are thought by most to result from enhanced platelet release in shock states. Others have proposed increased 5-HT release from the hypoxic intestine. An alternative or additional proposal is that $5-\mathrm{HT}$ is released from the lung itself. Neuroendocrine cells of the lung have been shown to contain 5-HT and studies have demonstrated a reduction in the 5-HT content of these cells in response to acute hypoxia. ${ }^{25}$ Electron microscopy has demonstrated exocytosis of 5-HT-containing granules from these pulmonary cells towards areas of the pulmonary vasculature. ${ }^{26}$ In humans, these 5-HT-containing neuroendocrine cells appear to be most numerous in the fetal and perinatal period. ${ }^{27}$ If these observations are true, then one may expect that increased 5-HT uptake ability of the neonatal lung is developmentally timed to coincide with a potentially increased 5-HT load from pulmonary neuroendocrine cells, thereby protecting the systemic circulation from an excessive 5-HT load. Such an arrangement would lead to low circulating 5-HT concentrations, as was demonstrated by our data.
The regulation of circulating 5-HT concentration appears to be of a complex, multifactorial nature. This study serves to highlight differences in circulatory 5-HT concentrations in newborn vs. adult respiratory failure and provide new, original data for further studies into the nature of 5-HT metabolism in the newborn.

\section{REFERENCES}

1. Kusajima K, Ozdemir A, Webb WR, Wax SD, Parker FB Jr. Role of serotonin and serotonin antagonist on pulmonary hemodynamics and microcirculation in hemorrhagic shock. J. Thorac Cardiovasc Surg. 1974: 67:908-914.

2. Makabali GL. Mandal AK. Morris JA. An assessment of the participatory role of prostaglandins and serotonin in the pathophysiology of endotoxic shock. Am J Obstet Gynecol. 1983: 145:439.

3. Meuleman TR, Hill DC, Port JD, Stanley TH, Pace NL, Mohammed SF. Ketanserin prevents platelet aggregation and endotoxin-induced pulmonary vasoconstriction. Crit Care Med. 1983; $11: 606-611$.

4. Sibbald W. Peters S. Lindsay RM. Serotonin and pulmonary hypertension in human septic ARDS. Crit Care Med. 1980. 8:490-494.

5. Hechtman HB, Shepro D. Lung metabotism and systemic organ function. Circ Shock. 1982: 9:457-467

6. Kerstein MD. Kohler J. Gould S. Moseley P. Pulmonary extraction of biogenic amines during septic shock. Am Surg. 1982; 48:552-554

7. Kerstein MD. Cronau LH. Mandel SD, Gillis CN. Effect of hemorrhagic shock on 5-hydroxytryptamine removal by the lung. Am Surg. 1982: 48:644-646.

8. Dobuler KJ. Catravas JD. Gillis CN. Early detection of oxygeninduced lung injury in conscious rabbits. Am Rev Respir Dis. 1982: 126:534-539

9. Olson EB, Ghias-Ud-Din M. Rankin J. Serotonin uptake and metabolism in isolated, perfused fetal, newborn and adult rabbit lungs. Lung 1983:161:173-179.

10. Sasa S. Blank CL, Wenke DC, Sczupak CA. Liquid-Chromatographic determination of serotonin in serum and plasma. Clin Chem. 1978: 24:1509-1514.

11. Scheffe $\mathrm{H}$. A method for judging all contrasts in the analysis of variance. Biometrica. 1953; 40:87-104.

12. Lucas A, Bloom SR, Aynsley-Green A. Vasoactive intestinal peptide (VIP) in preterm and term neonates. Acta Paediatr Scand. 1982: 71:71-74.

13. Pipkin FB, Smales RC. A study of factors affecting bloxd pres sure and angiotensin II in newborn infants. J Pediatr. 1977: 91:113-119.

14. Kopelman AE, Dombrowski D. Engelke SC. Louis TM. Plasma prostaglandin $E_{2}$ and $F_{2}$ in preterm infants: association with respirator distress syndrome and patent ductus arteriosus. Prostagland Leukotriene Med. 1983; 10:423-431.

15. Tagari PC. Boullin DJ. Davies CL. Simplified determination of serotonin in plasma by liquid chromatography with electrochemical detection. Clin Chem. 1984: 30:131-135.

16. Jones JB, Roswell A. Fetal 5-hydroxytryptamine levels in late pregnancy. J Obstet Gynecol. 1973; 80:687-689.

17. Mitchell RG, Cass R. Histamine and 5-hydroxytryptamine in the blood of infants and children. J Clin Lab Invest. 1959; 38:595603 .

18. Hazra M. Benson S, Sandler M. Blood 5-hydroxytryptamine levels in the newborn. Arch Dis Child. 1965: 40:513-515. 
19. Berman JL. Justince P. Hsia DY. The metabolism of 5-hydroxytryptamine (serotonin) in the newborn. J Pediatrs. 1965: 67:603608 .

20. Wilson RG, Davis RE. Vitamin $B_{6}$ intake and plasma pyridoxal phosphate concentrations in the first few weeks of life. Acta Paediatr Scand. 1984: 73:218-224

21. Whaun JM. The platelet of the newborn infant. Thrombos Diathes Hacmorrh. 1973; 30:327-333.

22. Suarez CR, Menendez CE. Walenga JM. Fareed J. Neonatal and maternal hemostasis: value of molecular markers in the assessment of hemostatic status. Semin Thrombos Hemostas 1984: 10:280-284.

23. Teague WT. Raj JV. Braun D. Clyman RI, Bland RD. Mecha- nism of increased lung fluid filtration during lipid infusion in lambs. Pediatr Res. 1985,14, pt 21:367A.

24. Vincent JL, Degaute JP, Domb M, Simon P. Berre J, Vandesteene A. Ketanserin, a serotonin antagonist. Chest. 1984: 85:510 513.

25. Keith IM, Wiley LA, Will JA. Pulmonary neuroendocrine cells: decreased serotonin fluorescence and stable argyrophil-cell numbers in acute hypoxia. Cell Tissue Res. 1981; 214:201-205.

26. Lauweryns JM. Cokelaere M. Deleesnyder M. Liebens M. Intrapulmonary neuroepithelial bodies in newborn rabbits. Cell Tissuc Res. 1977: 182:42.5-440.

27. Cutz E. Neuroendecrine cells of the lung. Exp Lung Res. 1982: $3: 185-208$. 